\title{
Management and Monitoring of RFID- based Cutting Tool Information for Integrated Manufacturing
}

\author{
Mior Uzair Mior Hassan ${ }^{\# 1}$, Aini Zuhra Abdul Kadir ${ }^{\# 2}$ \\ ${ }^{\#}$ Faculty of Mechanical Engineering, Universiti Teknologi Malaysia, UTM Skudai, Johor, Malaysia \\ uzair6791@yahoo.com \\ 2 aini@mail.fkm.utm.my
}

\begin{abstract}
The demand of integrating manufacturing design and process planning with actual production activities such as cutting tool information is essential to enhance planning efficiency as well as improve simulation accuracy. However, cutting tools information that involves static and dynamic data is difficult to track causing the planning and simulation activities to be isolated, using outdated information and lack of reliability. This paper presents the initial functions of an Integrated Cutting Tool Management and Monitoring system (ICTMMs) utilizing RFID technology. RFID is used as a device to identify individual cutting tool as well as to track cutters data at production floor. Integration is possible with the use of STEP-NC as the exchange data format. User interface is designed using Labwindows. General overview are discussed based on STEP-NC input file. The development of ICTMMs helps to simplify management of cutting tool at production floor and support the integration of tool information throughout the manufacturing chain.
\end{abstract}

Keyword-Tool management, RFID, STEP-NC

\section{INTRODUCTION}

Integrated manufacturing environment involves continuous interaction of various computer-aided (CAx) systems functions to ensure full information can be utilized in assisting various manufacturing activities. For example, during production planning activities, cutting tools data is essential for effective machining operation which is normally obtained beforehand based on operator's experience, catalogues or any theoretical documents. Following that, a complete product data is supplied to Virtual Machining System (VMS) to be verified through computer simulation, before the actual machining commences. Accurate machining simulation requires not only planned cutting tools details, but demands tools' information portraying true production floor data. The reliability of the simulation results therefore, depends on the information supply from CAx system with verification from production floor.

Unfortunately, information supply regarding cutting tools from production floor is still insufficient since cutters are hardly being tracked and traced. This is also due to the weakness of traditional information management method in managing static and dynamic data of the cutting tools. Static data refers to the specification details of the cutting tools located at the production floor. Currently, cutting tools are available in various types and multiple functions. High amount of individual cutting tools in production floor results in an increase of difficulty in handling these cutters' information. Thus, performing inventory control is a big challenge in order to ensure accurate selection of tools in terms of its type, geometry, and expected tool life. On the other hand, dynamic data refers to the information of cutting tool that changes over its usage within certain period of time. One example of dynamic data is tool life where it decreases after being used when performing any machining operation. Since tool life is important to determine the exact time for tool changing, therefore, it is crucial to identify the most economical strategic time to perform this action [1]. This is important to minimize the total cost since it involves stopping production, turn-off machine, loosen and tighten tool holder, selecting and changing tool, set-up machine, calibration and perform several times of inspection and test-run before the machine is allowed to be operated again. The time consumed for these activities are considered as non-value added downtime, thus, is not favourable. In addition, an early change of tool or premature tool removal will results in an increase of tool cost because the tool life is not fully utilized. On the other hand, late changing of tool will also cause an increase in labour cost because the products may need to be reworked again. Hence, performing tool management actively in production floor will be beneficial in overcoming the above mentioned issues.

Mostly, Computer Numerical Control (CNC) machines are capable of performing wide variety of operations. This flexibility leads to a frequent movement of cutting tools between tools storage and workstations. In other words, cutting tools distribution and tracking becomes complex, and should be considered in developing a good tool data management. Based on these reasons, production floor nowadays can no longer depends on manual cutting tool inventory control, hence proper tool management and monitoring system is needed. This system 
should be able to simplify management and decrease the risk of error regarding tool data record and selection. To eliminate manual data collection, one way is to design a system that utilizes sensors such as RadioFrequency Identification (RFID). RFID serves several important benefits such as enable quick response, portable, cover wide range of application and available in cheap price [2]. The sensor system is able to collect information at production floor, and then displays the information via user interface to enable human control over the designed system.

Once the cutting tool data is collected and managed at the production floor, the system must presents these data in a strategic format that can be used throughout the CAx system including VMS. This is to improve simulation activities with updated data. For that, presenting the cutting tool data in physical data model based on Standard for The Exchange of Product model data for Numerical Control (STEP-NC) will be a good approach. STEP-NC also known as ISO 14649 is a newly developed standard based on high level data model serves several benefits to enable data integration between the CAx systems. STEP-NC data structure is comprehensive, able to work with rich information including multiple operations, machine tool capability and cutting tool information.

Thus, the objective of this study is to present the initial functions of a developed system called Integrated Cutting Tools Management and Monitoring system (ICTMMs). ICTMMs utilized RFID sensors to track and trace cutting tools at production floor. The main interface was designed for user to perform cutting tools management and monitoring. To assist VMS, the designed system used STEP-NC data format as a physical file.

The rest of the papers are arranged as follows: Section 2 Literature review, Section 3 System development, Section 4 System function and finally Section 5 Conclusion and future work.

\section{LITERATURE REVIEW}

This section discusses several previous works relevant to this study and is divided into three sections: Section A. Management and monitoring of cutting tools, Section B. RFID applications and Section C. Data Integration using STEP-NC.

\section{A. Management and monitoring of cutting tools}

In the recent years, many researchers have identified various challenges in effectively managing cutting tools which include tool life management, preventative maintenance, and tool replenishment. For example, Cheng et al. [3] discuss comprehensively regarding cutting tool management issue in three levels; tool, machine and factory. Focussed at tool and machine levels, several issues were highlighted related to tool life which will affect tool selection, sequencing, replacement and replenishment. Fail to deal with these issue will result in poor performance of production floor in terms of tool utilisation and product output. Studies also show that any machinists' time is wasted for unfavourable activities [4]. This includes searching for tools and materials as well as idling activities when the required tools are unavailable when needed.

In general, the performance level of tool monitoring system is determined by two basic elements, which include the type and number of sensor used, and the approach to extract and analyse the signal. These elements usually undergoing signal processing and simplification methods. Strategic design of a monitoring system starts by identifying the common machining parameters used and the machining signal or physical elements which needs to be identified [5]. Following that, the selected sensors will be installed.

In order to idealize the management and monitoring of cutting tools, numerous frameworks have been proposed intensively by previous researchers. Byrne et al. [6] suggests a framework for tool monitoring, utilizing many possible sensors that are available and reasonable to be used. The work emphasizes that the most suitable selection of sensor must be made based on the target function and required signals. For milling operation, tool monitoring overview is presented by Prickett et. al [7], concerning tool identification, tool wear and tool breakage. It is widely accepted that most of the proposed approaches of monitoring system normally placed external sensors.

An effective cutting tool management may assists process planners in the process of making an accurate cutter selection. Leung and Hui [8] present a dynamic management model for cutting tools. This is to ensure favourable machining quality, by considering the wear level of the tool as well as the type of machining to be executed. The designed management system helps to determine optimal economic tool life, which afterwards decides the preventive actions based on dynamic evaluation programme carried out on the tool. The designed system proved that systematic tool management system is beneficial in controlling the product quality and support cost effective machining.

Moving towards a Flexible manufacturing system (FMS), several studies embedded the resource management system into a proper management and monitoring of cutting tools $[9,10]$. The performance of FMS mainly depends on proper management approach that deals with resources utilization and scheduling, thus highlight that tool management is the most dynamic and critical facility in FMS and requires keen attention. For example, Meseguer and Gonzales [11] suggest a methodology of cutting tool management that aims to solve tools loading 
and scheduling. The proposed system testified integration with computer-aided process planning, enable alternatives of tool listing that are compatible with scheduling. The proposed tool manager reduces the scheduling interferences, improves the flexibility to react with tool wear and perturbations within production system. The idea of integration is therefore a strategic approach for further innovation of cutting tool management system.

\section{B. Radio-Frequency identification sensor application for management and monitoring}

As mentioned, the use of sensors is important for management and monitoring purposes. Nowadays, RadioFrequency Identification (RFID) sensor has emerged as a promising technology with benefit potential in various applications in manufacturing including management and monitoring. A relevant RFID standards to be referred are the International Organization for Standardization's ISO/IEC 18000 standard [12]. The standard consists of the various parts, under the general title 'Information technology-Radio frequency identification for item management'. The main advantage of RFID is its nature that allows automatic, non-contact identification of objects, and afterwards permits data storage in small electronic circuits, which is particularly portable. Traditionally, barcode system is used to automate the process of collecting data. Its advantages over barcode are quicker response time, more information storage, higher durability, better read/write ability and does not require line of sight $[13,14]$.

Industrial practitioners have discussed about centralizing control system in order to enable manufacturing enterprises to achieve more flexibility, high agility and reconfiguration abilities. Barenji et al. [15] propose a Distributed Control System that utilized RFID sensor to realize accurate and just-in-time data acquisition. Multiagent system architecture is designed with RFID gate equipped at different stations for monitoring purpose. The system has a user interface and a database. The results prove that RFID system is the key to enable effective monitoring method, relevant to be employed for strategic tool management system.

For cutting tools, the use of RFID sensor in detecting and comparing tool identification number, tool life management, human input reduction and error reduction have been utilised [16, 17]. For example, Denkena et al. [18] present a concept of tool management that enables cooperation between tools and machine tools. Their main objective is to develop empirical tool wear model for online tool condition assessment, also utilised RFID to enables a direct communication between single tools and the main system. It can be concluded that their architecture and algorithms are designed systematically to enable tool wear estimation and condition-based tool management. At the same time, RFID technology became essential to complete the system functionality.

A modern control system is able to assist the manufacturing activities towards higher flexibility, sustainable and operative with minimum human interface. For instance, Stavropoulos et al. [19] discusses the design of management and monitoring system that consists of two mechanisms; adaptation and monitoring. Adaptive Control (AC) method helps in optimizing machining variable, while application of sensors deal with machining parameters measurement. The work demonstrates the idea of collecting information from machine and instantly uses the data to assist machining job to be operated. However, it should be mentioned that the use of dedicated sensor increases the equipment cost of a system and may be impractical for industrial applications. Thus, the using of an economically advantaged modern sensor such as RFID is more favoured by the industry.

Guoxin et al. [20] propose a methodology of tool management and control process. RFID is used as the main element in the tool usage stages that enables user to record real time information, increase efficiencies and avoid mistakes regarding tool utilization and management. Similarly, Sun and Jiang [21] also propose cutting tool monitoring system based on RFID technology. Their framework consists of four layers which include supporting hardware, data, system modules and application layers. The framework running mechanism starts with analysis of the given part, selection of cutting tool, use RFID to configure cutting tool states from tool magazine information, execute static and dynamic scheduling modules, and lastly perform tool life estimation. The functionality of their proposed framework is possible to be extended in order to integrate the collected information between the proposed system and any virtual systems.

Managing of cutting tools information with RFID also helps to improve manufacturing operation by providing visibility to assets, supplies and personnel. Vogel et al. [22] presents RFID-based tool tracking for automated management and maintenance. By using ISO 15693 protocol, and WinRFID as middleware driver, the tracking system consists of database with four tables such as locations, cutting tools, check-in/check-out and utilization was developed. However, the management system lacks the production floor information. Thus, further study should be done with extended scope that includes cutters information integration. Gordana et al. [23] verify the novel use of RFID sensor in development of automatic cutting tool selection system. Both of these studies reveal the challenge in practical use of RFID sensor that requires effort in developing graphical user interface which are compatible with the sensor driver. 


\section{Data Integration using STEP-NC}

Standard for The Exchange of Product model data for Numerical Control (STEP-NC) published under the family code ISO 14649 is a new language for CNC machine controller [24-27]. The development of this global common standard provides a complete data model for $\mathrm{CNC}$ programming. This data structure can be used to describe detailed machining description including workpiece geometry, feature placement, machining step, process parameter and tool specifications. Therefore, with STEP-NC, the communication between CAx chain is upgraded and extended to the point where potential machining information can be shared throughout for output benefits. In other words, the data model in STEP-NC provides an interchangeable interface between ComputerAided Design/Computer-Aided Manufacturing (CAD/CAM) system and CNC.

For the past 16 years, there are many studies on STEP-NC applications being conducted in order to expand its potentials, thus, proving and promoting its advantages. During 2008 to 2013 period of time, survey shows that research work on knowledge-based and STEP-compliant technique utilization was increased [28]. Comprehensive reviews on STEP-NC can be found in few previous studies [29-31]. Some of the reported STEP-NC based works showed that data integration can be performed with variations of targeted applications. For example, Allen [32] shows the application of STEP-NC in design of Computer-Aided Process Planning (CAPP) and CAM. They present the automatic generation of STEP-NC code through agent-based decision making. $\mathrm{Xu}$ [33] also adopts the STEP-NC as a common language to simplify data exchange within manufacturing process chain, with seamless flow of product information. This supports the statement that STEP-NC is firm to substitute G-codes and enable all data integration from any CAD/CAM systems. Lee et al. [34] develop a PC-based open architecture milling machine, run by STEP-NC and claim that the design can be easily expanded and modified. It was also stated that it is possible to implement the STEP-NC system directly to any commercial machine tools.

Studies have been conducted to enhance the capabilities and expanding the applications of machining simulation. For example, development of High-Fidelity Machining Simulation (HFMS) can keep historical data for future simulation analysis, minimize machining time, and able to recognize real behaviour of the machine tool [35]. The results proved that the capabilities to produce an informative and truthful simulation are achievable by utilizing high-level STEP-NC data model.

In 2010, Zhao and Xu [36] presents the application of STEP-NC in their monitoring system to enable realtime acquisition of production and process data and feedback to process control. The data structure provides semantic level information that enable automatic reasoning, adjustment and feedback function in monitoring manufacturing process. STEP-NC is essential in the designed architecture, proving that the data model data model is suitable for the entire manufacturing system. This data structure also ideally works with their algorithm that involves workingsteps resequencing, micro inspection programs and measurement of results analysis or feedback system.

Peng Li et al. [37] propose a communication framework based on STEP-NC as information input from $\mathrm{CAD} / \mathrm{CAM} / \mathrm{CAPP}$, which allows monitoring of tool wear becomes an efficient method to transfer related data from sensor device for further intelligent analysis and action. The unified communication framework also presents a harmonize data flow with real time industrial Ethernet fieldbus, which is used for automation controlling and monitoring.

In 2014, Peng and $\mathrm{Xu}$ [38] presents a module of energy monitoring in machining in order to achieve energyefficient CNC machining system. The standardised data format of STEP-NC became the key factor to provide integrated energy data model for monitoring. With standardised energy data across different activities, STEP$\mathrm{NC}$ is necessary in order to improve energy efficiency of machine tool and operation strategies.

Furthermore, the capability of STEP-NC data format also being discussed by $\mathrm{Hu}$ et al. [39]. The study proposes Closed-loop and Self-learning STEP-NC (CS-STP), architecture of machining system that includes functions such as process planning, condition monitoring function, information collection and analysis. The system loop is completed with the use of CNC controller called HITCNC, stand for Harbin Institute of Technology Computer Numerical Control, that helps to interpret STEP-NC file directly and adaptively. STEP$\mathrm{NC}$ again takes a central part in $\mathrm{CNC}$ controller in the closed loop and self learning machining system.

Towards total control over machining process, complete information from CNC machine needs to be collected as feedback for diagnosis, hence enabling perfect monitoring system. The vision becomes clearer with STEP-NC standard that enables bi-directional information exchanges between manufacturing digital chains. However, the system architecture is still in the process of research and development. In 2015, Danjou et al. [40] propose a concept of information transfer between CNC machine CAM station. With STEP-NC as the architecture language, the manufacturing loop is designed based on Product Lifecycle Management (PLM), enables manufacturing information to be captured. Related work being done by Ridwan et al. [41] that focus on how to optimally regulate the feedrate through the development of monitoring system. Since the aim is to 
optimize specific manufacturing processes through feedrate parameter defined in STEP-NC, this work can be a guideline in order to enhance machining simulation through information control of cutting tool parameter.

It can be concluded that, STEP-NC data structure provides adequate information integration throughout manufacturing system. In this study, cutting tools information sharing between production floor and VMS is realised in order to assist and improve simulation capability. Apart from comprehensive data structure, the proposed system development also includes the application of sensor at production floor to simplify cutting tool data management and monitoring.

\section{III.SYSTEM DEVELOPMENT}

As described, the main objective of Integrated Cutting Tool Management and Monitoring system (ICTMMs) is to enable integration of cutting tool information between production floor and any virtual system. At production floor, ICTMMs is able to perform monitoring function including registration, identification and tracking cutting tool used in $\mathrm{CNC}$ machine. The system afterwards is able to present cutting tool information based on STEP-NC data model and then update the cutting tool data in STEP-NC file for simulation, hence assist VMS for integrated manufacturing practice. Figure 1 shows the general overview of ICTMMs.



Fig. 1. ICTMMs General Overview

Based on Figure 1, ICTMMs is designed to act as an intermediatory platform between the CNC machine and the VMS. The system is divided into two functions; cutting tool management and cutting tool monitoring, A management interface is designed to provide user control for cutting tool ID identification, specification inputs and data storage. On the other hand, the monitoring interface provide functions for cutting tool data update, starting with STEP-NC physical file loading and data extraction, followed by tool validation and life estimation. The system interface is coded using Labwindows, a C programming tools and is able to read a STEP Part 21 file as input.

At the CNC machine level, RFID sensor is utilised to scan cutting tool ID and tool life estimation. RFID control software works as part of ICTMMs function for sensor management, operation control and power control. Each cutter available in tool magazine is tagged and tool tag scanning enable cutter identification and further data management. To enable tool life estimation, vibration sensor, signal processing unit and data acquisition (DAQ) system were used to create stopwatch for cutter-workpiece contact. DAQ hardware collect analog input from vibration sensor creating sinusoidal wave, displayed at DAQ output software. Starting point is defined when the CNC machine run without any machining process. When a machining task is performed, the magnitude of the sinusoidal wave increased, and the stopwatch measurement started. The counting is stopped whenever the magnitude of the output wave below the starting point, indicate that the tool is off contact with workpiece. At the same time, ICTMMs provides a section for software control and enable user to activate sensor and signal processing unit.

At VMS level, ICTMMs uses ISO 14649 Part 10, 11 and 111 [24-27], representing data structures for general machining operation, technology specific for milling and cutting tools for milling, respectively. STEP- 
NC Part 21 file is utilized to enable data transfer between CNC level and VMS through ICTMMs. The ICTMMs enables cutting tool information being extracted and mapped with the registered cutting tool in the database under the STEP-NC environment. The identification and validation functions were developed to prevent error in selecting cutting tools before any machining task being performed. Before the physical file is used as input for simulation, the system enables tool data update based on data collected by the monitoring and management functions.

The target function of this monitoring system is to enable cutting tool identification, tool tracking, status confirmation as well as error checking regarding the selection of cutting tools. Figure 2 shows the workstation set-up for ICTMMs development.

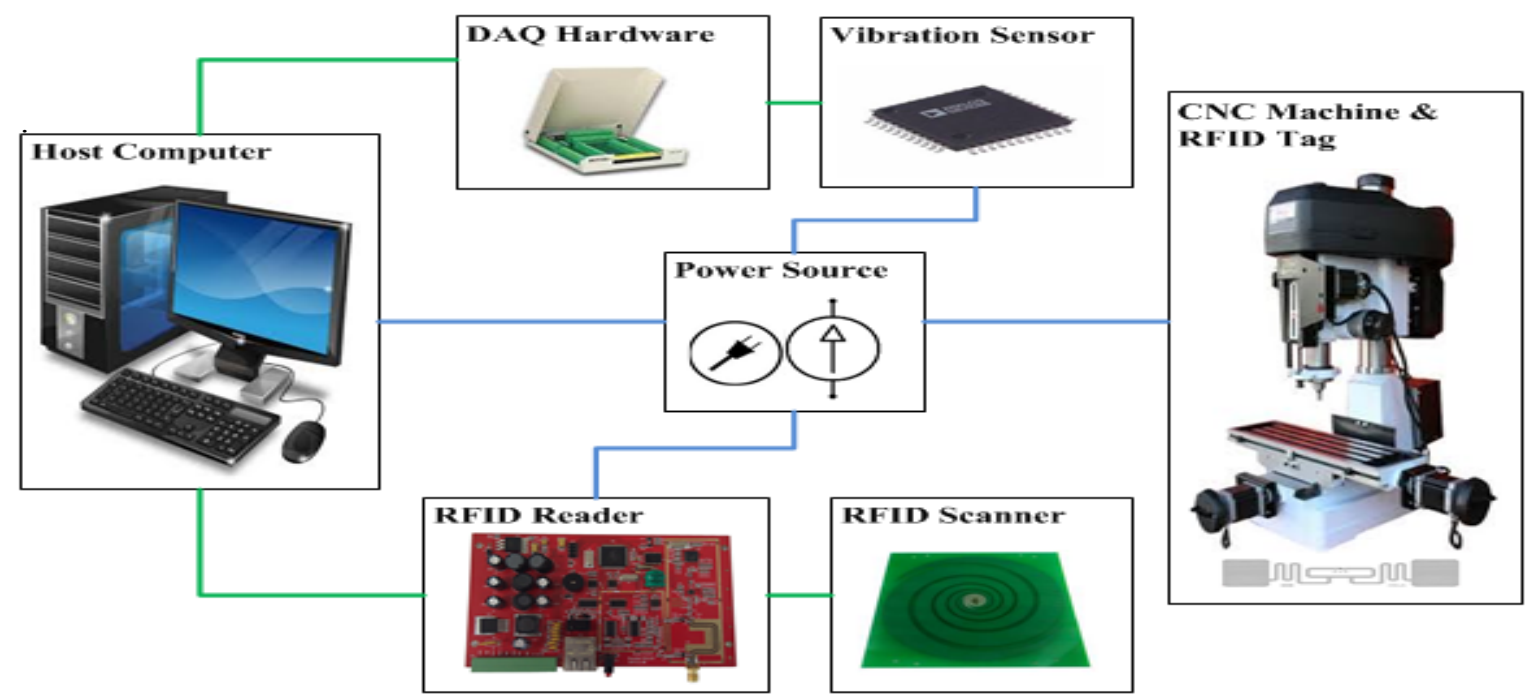

Fig. 2. ICTMMs Workstation Set-up

The workstation consists of a 3-axis CNC vertical milling machine, a standard open system computer as a controller host and RFID system component as the sensor. For RFID set-up, several specifications and settings are determined. Figure 3 and Figure 4 illustrate the RFID system connection diagram and RFID system component, respectively. The sensor system consists of RFID reader 1100 (4-port), communication interface panel with $+9 \mathrm{~V}$ DC socket power port, RJ45 communication port connected into network via network cable, $902 \mathrm{Mhz}$ to $928 \mathrm{Mhz}$ operating frequency, equipped with $220 \mathrm{~V}$ AC input, $+12 \mathrm{~V}$ DC output power convertor, average power dissipation less than $20 \mathrm{~W}$, net weight less than $1 \mathrm{Kg}$ and operation temperature between $-10^{\circ} \mathrm{C}$ to $+55^{\circ} \mathrm{C}$. The RFID tag is placed on each tool magazine compartment so that each unique ID code can be assigned with specific individual cutter.

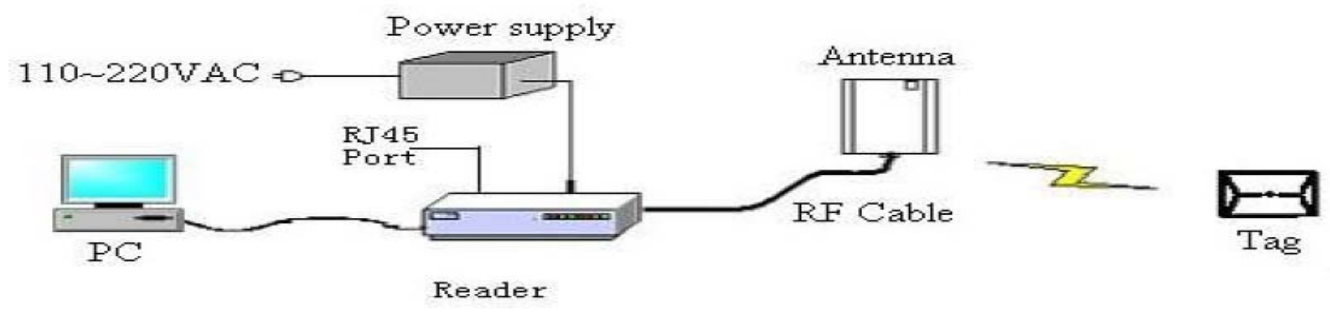

Fig. 3. RFID system connection diagram
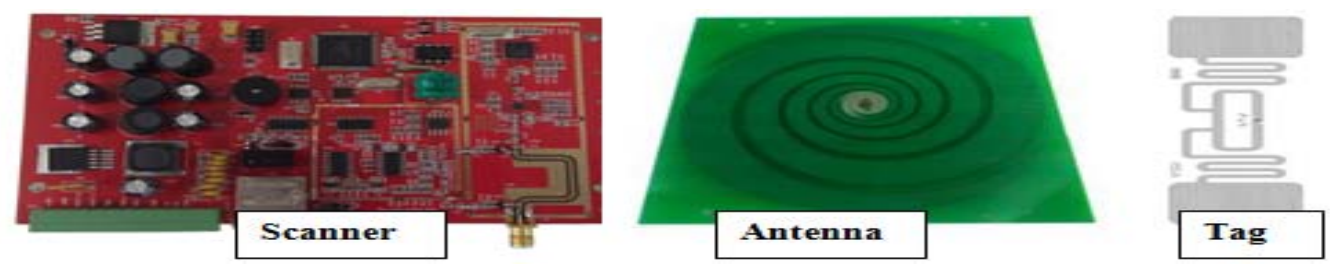

Figure 4. RFID system components 
ICTMMs database is designed so that each IDs have their own text field with input for specification details, hence enable user to record the information including cutting tools location in the storage. Table 1 shows the cutting tool information included in the database. From the table, there are six cutters being stored having variation of unique identification that define the cutter numbers, cutter types and diameters. For example, Cutter1-Endmill6MM simply defines as cutter number 1 is of endmill type with $6 \mathrm{~mm}$ diameter. Other specifications include the number of flute and material.

TABLE I. List of Cutting Tool in Database

\begin{tabular}{|cccc|}
\hline TOOL ID & $\begin{array}{c}\text { DIAMETER } \\
\text { (MM) }\end{array}$ & TYPE/NO. OF Flute & Material \\
\hline Cutter1-ENDMILL 6MM & 6 & Solid Endmill/4 & HSS-Cobalt \\
\hline Cutter2-ENDMILL 8MM & 8 & Solid Endmill/4 & HSS-Cobalt \\
\hline Cutter3-ENDMILL 10MM & 10 & Solid Endmill/4 & HSS-Cobalt \\
\hline Cutter4-ENDMILL 6MM & 6 & Solid Endmill/4 & Standard Carbide \\
\hline Cutter5-ENDMILL 8MM & 8 & Solid Endmill/4 & Standard Carbide \\
\hline Cutter6-ENDMILL 10MM & 10 & Solid Endmill/4 & Standard Carbide \\
\hline
\end{tabular}

Sample of STEP-NC Part 21 file is shown in Figure 5. The same ID is used in the STEP-NC physical file and the specifications are also stated in the data model. Therefore, validation of the assigned cutting tool in STEP$\mathrm{NC}$ file and available cutters in database are based on its ID and specifications. The system then extracts the cutting tool data and validates its status in terms of availability and remaining tool life.

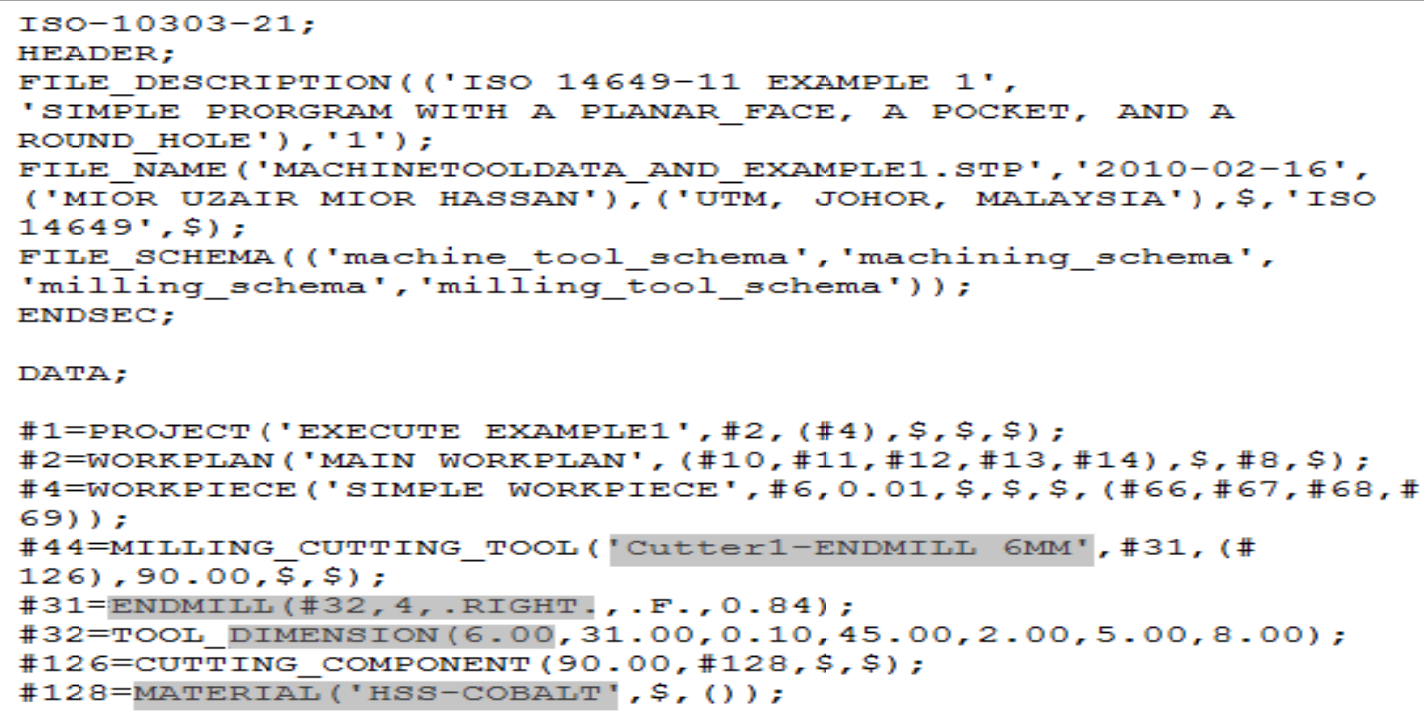

Figure 5. Sample of STEP-NC Part 21 file

\section{IV.SYSTEM FUNCTION}

ICTMMs process flow is designed and presented in Figure 6. First, the database is stored with cutting tool information upon registration. Cutting tools that are available in a tool magazine are tagged with RFID tags. Identification of cutting tool is performed when tagged cutting tools passes through the RFID scanner equipped at the CNC machine. RFID activation is then performed through its own control software, generally using software development kit (SDK). Programming work is done to enable scanned tag code is forwarded to the ICTMMs for data input. Each tag is then registered in the system database based on its unique code numbers. Within the database, each code numbers is assigned with ID based on STEP-NC entity. Each ID has its own section in the database that stores cutting tool specifications and tool life. These data registration input is provided in the user interface. 


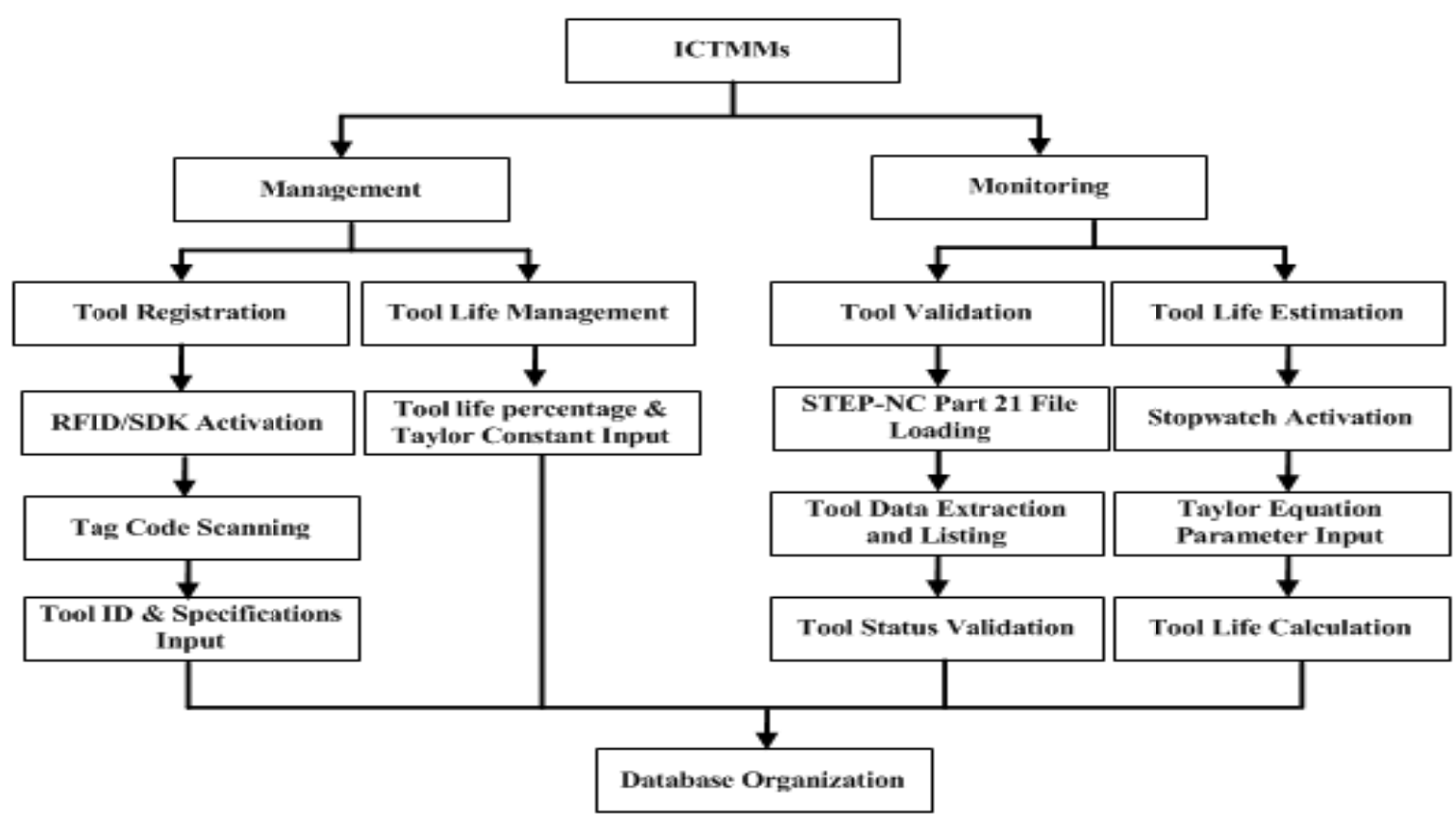

Fig. 6. ICTMMs Process Flow

For tool validation, the system utilises cutter data prepared by planner. The designed interface enable Part 21 file to be loaded and cutter data will then be extracted. Assigned cutter is listed and tool ID comparison is performed. Based on the database content, the availability of the assigned cutters is validated.

For tool life management, new cutters with $100 \%$ of remaining tool life will first be registered. Taylor's tool life equation [42-44] is adopted to estimate remaining tool life, therefore Taylor constants are required when registration is performed. Stopwatch is designed using vibration sensor to estimate tool-workpiece contact, to be included in the Taylor's tool life equation. After a machining task is performed, ICTMMs will estimate the remaining tool life and update the information in the database.

A user interface is designed as a medium to enable interaction between user and ICTMMs system. Figure 7 shows the developed prototype of ICTMMs with the ability to provide two main functions:

(i) Managing cutting tool database

(ii) Monitoring cutting tool for machining

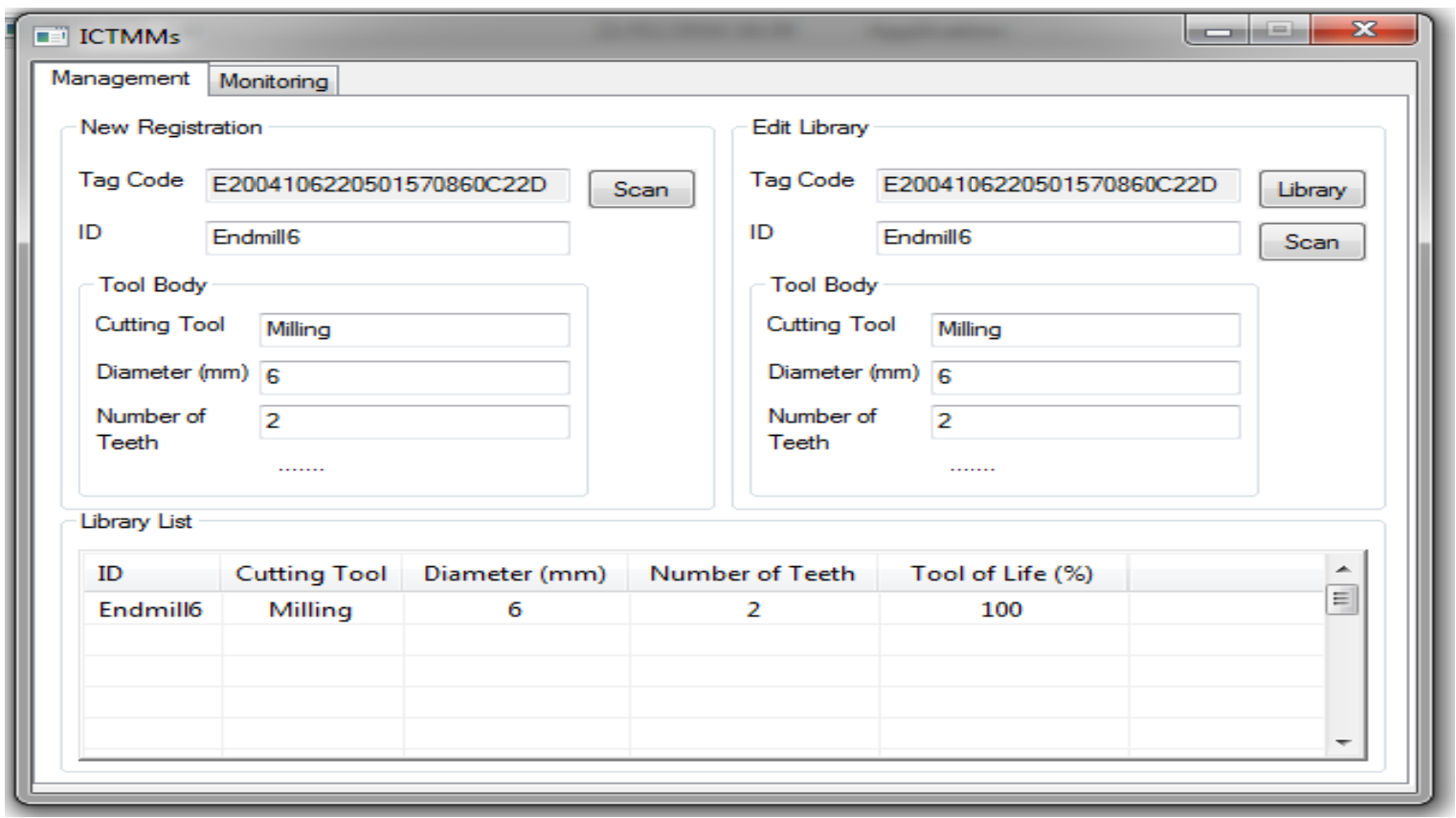

a) Tool management 


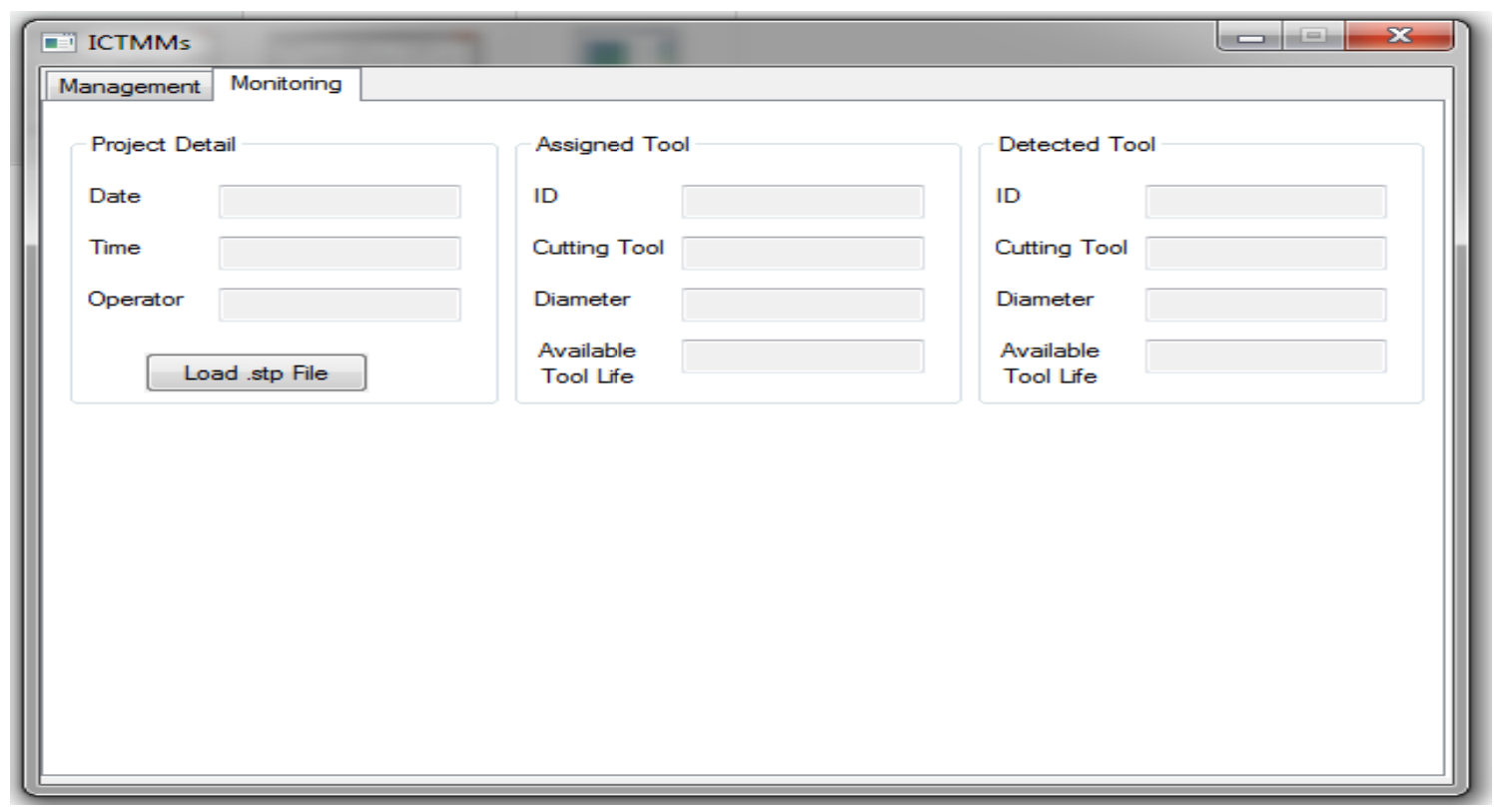

b) Tool monitoring

Fig. 7. ICTMMs user interface for a) Tool management and b) Tool monitoring

The user interface shown in Figure 7 is designed comprising of two functions, which includes management and monitoring functionalities. Each function provides menus, information display and user input platform for registration, identification and tracking, as well as the updating functions. The interface is also designed to enable user to control over the database and give commands to the RFID sensor system. The management tab provides tool registration function that is based on specific RFID tag code. User is able to activate the RFID scanner to obtain unique tag code that will be registered with tool ID and specification. The list of registered tools is then displayed to enable information management including specification editing and tool tracking.

Another tab provides the monitoring function interface. Details of cutting processes are recorded and the interface provides a platform to load STEP-NC file with stp format. The assigned tool information is extracted from the file and the system will automatically check the availability of the tool within the database. Options to select other tools are provided if the tool assigned is not available within the database. Any changes of tool information will be recorded to update the STEP-NC file. Identification of tool mounted at CNC machine is performed to confirm that the accurate tool is used at production floor. The system then provides notification and options if detected cutting tool is not registered or did not match the assigned tool specification. Any changes of tool made by user are recorded to update the STEP-NC file. Final confirmation will be made by user to update the STEP-NC file. As a result, management method of cutting tool resources at production floor are simplified. By utilizing STEP-NC data format, the tool information is used to assist VMS by updating tool information, hence improve the simulation result accuracy.

\section{CONCLUSION AND FUture WORKS}

Managing cutting tool is indeed an important issue at production floor. Proper tool management system helps to simplify information recording and reduce data lost. Monitoring system equipped with sensor enable tool identification and prevents error of tool selection. The information can be forwarded to Virtual Machining System, to assist simulation with updated tool data. Simulation are no longer depend entirely on planner tool decision, but also include cutting tool information from production floor, hence producing reliable and practical simulation result.

To improve the performance of ICTMMs, further study should be done to extend monitoring function and improve the result accuracy. For tool life estimation, other types of sensors may be needed to enable direct detection of tool-workpiece contact, which will improve the sensitivity of the tool contact stopwatch. Theoretical study is needed to support tool life estimation, such as application of Taylor's tool life equation. This includes the review on method used to determine the equation's parameter in order to improve the accuracy of estimated tool life result. The method to determine how available tool life can be improved in terms of percentage limits. The limits should consider the differences in total tool life. Effort can be done to enhance the management function that can support other inventory control such as cutting tool scheduling. Cutting tool utilization can also be maximised by strategic scheduling, where cutting tool with specific available life can be assigned to machining task with suitable cutting time. Since several types of cutting tool can be resharpened, improvement can be made to include resharpen status in the cutting tool database. With an ideal tool 
management solution, monitoring system became more flexible for further innovation, including the use of multiple sensors to expand the system functionality.

Further study need to be done regarding the application of RFID system specifically for cutting tool. The operating condition in manufacturing environment may required specific design factor to be highlighted such as tags material, size, temperature resistance and individual tag cost.

\section{ACKNOWLEDGMENT}

The research work is jointly funded by Ministry of Education, Malaysia, and Universiti Teknologi Malaysia under Fundamental Research Grant Scheme (Vote 4F573).

\section{REFERENCES}

[1] Kara, S., D. Heeschen, F. Klocke, and K. Arntz, The 22nd CIRP Conference on Life Cycle EngineeringLife Cycle Oriented Milling Tool Management in Small Scale Production. Procedia CIRP, 2015. 29: p. 293-298.

[2] Mandeep Kaur, Manjeet Sandhu, Neeraj Mohan, and P.S. Sandhu, RFID Technology Principles, Advantages, Limitations \& Its Applications. International Journal of Computer and Electrical Engineering, 2011. 3(1): p. 151-157.

[3] Cheng, C.-Y., D. Barton, and V. Prabhu, The servicisation of the cutting tool supply chain. International Journal of Production Research, 2008. 48(1): p. 1-19.

[4] Gunasekaran, A., R. McNeil, and D. Singh, Activity-based management in a small company: A case study. Production Planning \& Control, 2000. 11(4): p. 391-399.

[5] Al-Habaibeh, A. and N. Gindy, A new approach for systematic design of condition monitoring systems for milling processes. Journal of Materials Processing Technology, 2000. 107(1-3): p. 243-251.

[6] Byrne, G., D. Dornfeld, I. Inasaki, G. Ketteler, W. König, and R. Teti, Tool Condition Monitoring (TCM) - The Status of Research and Industrial Application. CIRP Annals - Manufacturing Technology, 1995. 44(2): p. 541-567.

[7] Prickett, P.W. and C. Johns, An overview of approaches to end milling tool monitoring. International Journal of Machine Tools and Manufacture, 1999. 39(1): p. 105-122.

[8] Leung, L.C. and Y.V. Hui, Dynamic management of cutting tools for flexible and quality machining. International Journal of Production Research, 2000. 38(14): p. 3385-3401.

[9] Akturk, M.S. and S. Ozkan, Integrated scheduling and tool management in flexible manufacturing systems. International Journal of Production Research, 2001. 39(12): p. 2697-2722.

[10] Matta, A., T. Tolio, and F. Tontini, Tool management in flexible manufacturing systems with network part program. International Journal of Production Research, 2004. 42(17): p. 3707-3730.

[11] Meseguer, A. and F. Gonzalez, A methodology for cutting-tool management through the integration of CAPP and scheduling. International Journal of Production Research, 2008. 46(6): p. 1685-1706.

[12] ISO/IEC 18000 Information technology -- Radio frequency identification for item management. 2008, International Organization for Standardization.

[13] Ghouse Modin N. Mamdapur and I.U. Rajgoli, Implementing radio frequency identification technology in libraries: Advantages and disadvantages. International Journal of Library and Information Science, 2011. 3(3): p. 46-57.

[14] Trupti Lotlikar, Rohan Kankapurkar, Anand Parekar, and A. Mohite, Comparative study of Barcode, QR-code and RFID System. International Journal of Computer Technology and Applications, 2013. 4(5): p. 817-821.

[15] Barenji, R.V., A.V. Barenji, and M. Hashemipour, A multi-agent RFID-enabled distributed control system for a flexible manufacturing shop. The International Journal of Advanced Manufacturing Technology, 2014. 71(9): p. 1773-1791.

[16] Faltin, M., J. Aurich, and F.G. Kempf, An Approach to Identify RFID Application Potentials and to Implement Smart Tools, in Proceedings of the 6th CIRP-Sponsored International Conference on Digital Enterprise Technology, G. Huang, K.L. Mak, and P. Maropoulos, Editors. 2010, Springer Berlin Heidelberg. p. 433-447.

[17] Liukkonen, M., RFID technology in manufacturing and supply chain. International Journal of Computer Integrated Manufacturing, 2015. 28(8): p. 861-880.

[18] Denkena, B., M. Krüger, and J. Schmidt, Condition-based tool management for small batch production. The International Journal of Advanced Manufacturing Technology, 2014. 74(1-4): p. 471-480.

[19] Stavropoulos, P., D. Chantzis, C. Doukas, A. Papacharalampopoulos, and G. Chryssolouris, Monitoring and Control of Manufacturing Processes: A Review. Procedia CIRP, 2013. 8: p. 421-425.

[20] Guoxin, W., H. Nakajima, Y. Yan, Z. Xiang, and W. Lu. A methodology of tool lifecycle management and control based on RFID. in Industrial Engineering and Engineering Management, 2009. IEEM 2009. IEEE International Conference on. 2009.

[21] Sun, P.L. and P.Y. Jiang, A Framework for Implementing RFID-Based Cutting Tools Management System in a Machining Workshop. Applied Mechanics and Materials, 2012. 220-223: p. 360-363.

[22] Vogel, L., B.S. Prabhu, and R. Gadh, Development and Testing of an RFID-based Cutting Tools Tracking Application. 2 nd Hewlett Packard RFID Symposium, 2007: p. 18-19

[23] Gordana, O., T. Branko, L. Ognjan, S. Stevan, V. Djordje, B. Igor, and M. Ljubomir, An integral system for automated cutting tool selection. Scientific Research and Essays, 2011. 6(15): p. 3240-3251.

[24] ISO14649-1, Industrial automation systems and integration -- Physical device control -- Data model for computerized numerical controllers -- Part 1: Overview and fundamental principles. 2003, International Organization for Standardization.

[25] ISO14649-10, Industrial automation systems and integration -- Physical device control -- Data model for computerized numerical controllers -- Part 10: General process data. 2004, International Organization for Standardization.

[26] ISO14649-11, Industrial automation systems and integration -- Physical device control -- Data model for computerized numerical controllers -- Part 11: Process data for milling. 2004, International Organization for Standardization.

[27] ISO14649-111, Industrial automation systems and integration -- Physical device control -- Data model for computerized numerical controllers -- Part 111: Tools for milling machines. 2010, International Organization for Standardization.

[28] Yusof, Y. and K. Latif, Survey on computer-aided process planning. The International Journal of Advanced Manufacturing Technology, 2014. 75(1): p. 77-89.

[29] Hardwick, M. and D. Loffredo, Lessons learned implementing STEP-NC AP-238. International Journal of Computer Integrated Manufacturing, 2006. 19(6): p. 523-532.

[30] Li, P., T. Hu, and C. Zhang, STEP-NC Compliant Intelligent Process Planning Module: Architecture and Knowledge Base. Procedia Engineering, 2011. 15(0): p. 834-839. 
[31] Xu, X.W. and Q. He, Striving for a total integration of CAD, CAPP, CAM and CNC. Robotics and Computer-Integrated Manufacturing, 2004. 20(2): p. 101-109.

[32] Allen, R.D., J.A. Harding, and S.T. Newman *, The application of STEP-NC using agent-based process planning. International Journal of Production Research, 2005. 43(4): p. 655-670.

[33] Xu, X.W., Realization of STEP-NC enabled machining. Robotics and Computer-Integrated Manufacturing, 2006. 22(2): p. 144-153.

[34] Lee, W., Y.B. Bang, M.S. Ryou, W.H. Kwon, and H.S. Jee, Development of a PC-based milling machine operated by STEP-NC in XML format. International Journal of Computer Integrated Manufacturing, 2006. 19(6): p. 593-602.

[35] Kadir, A.A. and X. Xu, Towards High-Fidelity Machining Simulation. Journal of Manufacturing Systems, 2011. 30(3): p. 175-186.

[36] Zhao, Y.F. and X. Xu, Enabling cognitive manufacturing through automated on-machine measurement planning and feedback. Advanced Engineering Informatics, 2010. 24(3): p. 269-284.

[37] $\mathrm{Li}, \mathrm{P} ., \mathrm{T}$. Hu, and C. Zhang, A Unified Communication Framework for Intelligent Integrated CNC on the Shop Floor. Procedia Engineering, 2011. 15: p. 840-847.

[38] Peng, T. and X. Xu, A holistic approach to achieving energy efficiency for interoperable machining systems. International Journal of Sustainable Engineering, 2014. 7(2): p. 111-129.

[39] Hu, P., H. Fu, Z. Han, and D. Han. A closed-loop and self-learning STEP-NC machining system. in Advanced Intelligent Mechatronics (AIM), 2014 IEEE/ASME International Conference on. 2014.

[40] Danjou, C., J. Le Duigou, and B. Eynard, Closed-loop manufacturing process based on STEP-NC. International Journal on Interactive Design and Manufacturing (IJIDeM), 2015: p. 1-13.

[41] Ridwan, F., X. Xu, and G. Liu, A framework for machining optimisation based on STEP-NC. Journal of Intelligent Manufacturing, 2012. 23(3): p. 423-441.

[42] Meeting, A.S.o.M.E.W., F.W. Taylor, Ł. Kops, S. Ramalingam, and A.S.o.M.E.P.E. Division, On the Art of Cutting Metals--75 Years Later: A Tribute to F.W. Taylor. 1982: American Society of Mechanical Engineers, United Engineers Center.

[43] Taylor, F.W., On the Art of Cutting Metals. 1907: American society of mechanical engineers.

[44] Childs, T., K. Maekawa, T. Obikawa, and Y.Y. Yamane, Metal Machining Theory and Applications. 2000: John Wiley \& Sons Inc. 